\title{
De vencedores a víctimas: 25 años de memoria castrense Valentina Salvi
}

\author{
Valentina Salvi es Doctora en Ciencias Sociales \\ por la Universidad Estadual de Campinas, Brasil. \\ Investigadora de CONICET. Profesora de Teoría Social \\ de la Facultad de Ciencias Sociales de la Universidad \\ de Buenos Aires y de Sociología de la Cultura de la \\ Universidad de Tres de Febrero. \\ Mail: valentinasalvi@hotmail.com
}

\section{resumen}

Este artículo se propone abordar la memoria militar sobre la represión en Argentina, más específicamente, la memoria institucional del ejército, buscando reconocer los ciclos de construcción, deconstrucción y reconstrucción de sus narrativas sobre el pasado reciente. A lo largo de los últimos 25 años, en la memoria del ejército conviven tanto continuidades como transformaciones narrativas. Unas y otras son fruto de las negociaciones y confrontaciones que la institución mantiene, para dentro, con el relato hegemónico sobre la "lucha contra la subversión"; para fuera, con el discurso de los organismos de Derechos Humanos y la memoria de los desaparecidos. De allí que el interrogante primordial que anima este trabajo es cómo se articulan cambio y continuidad en la memoria de una institución para la cual el pasado es fuente de legitimidad e identidad, pero que al mismo tiempo se ve enérgicamente cuestionada por una sociedad que le exige respuestas por los crímenes cometidos. En suma, este artículo se plantea los siguientes interrogantes: ¿Cómo reproduce la memoria del ejército las representaciones que posibilitaron su criminalización y cómo se diferencia de la herencia del régimen de facto que la precede? ¿Cómo evolucionó a través de los años para adaptarse a nuevas situaciones y cómo mantuvo los sentidos y representaciones que conforman su identidad y tradiciones?

\section{palabras claves}

memoria / ejército / democracia / Argentina

\section{summary}

The aim of this paper is to analyze the military personnel's memory regarding illegal repression in Argentina. More specifically, it attempts to recognize the cycles of construction, deconstruction and reconstruction of the military narratives about the recent past. Within the last 25 years, military's memory has hold continuities and ruptures. These arise from the processes of both negotiation and confrontation that the military has had to deal with. These processes have been developed inwards, with their own hegemonic narrative about "fight against subversion" and outwards, especially in terms of the increasingly stronger discourse of the Human Rights organizations and the relatives of the disappeared. Therefore, the main question of this paper is how to analyse the changes and continuities that affect the memory of the military, for which the past is not only a source of legitimacy and identity but also a source of condemnation and justice claims that call into question its the institutional place as such. This paper also proposes to answer the following questions: How do the policies of memory of the military reproduce the representation that contributes to its criminalization and how does it attempt to make a difference in relation to the heritage of the previous dictatorships? How the narratives of the military have changed in the last years in order to adapt its discourses to the new contexts? How does the army manage to keep its corporative spirit, traditional practices, and identity alive in that adverse context?

\section{keywords}

memory / army / democracy / Argentina 
A pesar del silencio y el ocultamiento que rodea a la desaparición de personas en Argentina, el ejército y sus oficiales recuerdan los años de la represión, es decir, construyen y escenifican versiones sobre un pasado de violencia que lo tuvo como uno de los principales responsables. En efecto, el ejército y sus cuadros tienen un papel activo en la construcción de sus memorias puesto que, en los últimos 25 años, se vieron forzados a tomar posición frente a los debates que la sociedad civil mantiene sobre el pasado reciente. ${ }^{1}$ La imagen institucional que el ejército construye para sí y presenta a la sociedad argentina no está exenta de cambios, negociaciones y transformaciones pero tampoco de continuidades y repeticiones. De allí que este artículo se propone mostrar que la memoria institucional del ejército sobre la represión responde tanto a la continuidad de una matriz narrativa que refuerza la autovaloración de la institución castrense como una única comunidad moral, como a las transformaciones e innovaciones que le van permitiendo a la institución posicionarse frente al fortalecimiento de la memoria de los desaparecidos y al discurso de los organismos de Derechos Humanos.

Si bien Pollak (2006) afirma que cuando la memoria de una institución está suficientemente constituida, instituida y conformada, las cuestiones provenientes de los grupos externos no llegan a provocar la necesidad de reconfiguración; sin embargo, el propósito de este artículo es mostrar que la memoria institucional del ejército se ve afectada por problemas de credibilidad, aceptabilidad y organización que son parte del escenario de la memoria ${ }^{2}$ posdictadura en Argentina. Credibilidad, aceptabilidad y organización se vuelven, en estas páginas, ejes analíticos que permiten analizar el proceso de deconstrucción y reconstrucción de la memoria institucional del ejército en los últimos 25 años. En primer lugar, el criterio de credibilidad refiere a la producción de un relato coherente, verosímil y comunicable sobre el pasado reciente en lucha con otros discursos. En segundo lugar, el criterio de aceptabilidad permite atender a los dos ámbitos hacia los cuales se dirige la memoria castrense: hacia la comunidad militar y hacia la sociedad civil y el Estado. Para dentro, remite a la construcción de una memoria edificante que refuerza los sentimientos de pertenencia y autovaloración y que estimula la rememoración y transmisión con una fuerte carga afectiva a las nuevas generaciones de oficiales. Para fuera, da cuenta de las negociaciones, modificaciones, falsificaciones o reconstrucciones que se operan en la reconfiguración de la memoria del ejército para cuestionar la narrativa de los organismos de Derechos Humanos y para posicionarse con su relato en el escenario de la memoria. Y por último, el criterio de organización se ocupa del trabajo de encuadramiento y formalización de la memoria castrense que contribuye, por un lado, a reproducir la identidad narrativa de la institución a lo largo del tiempo; y por otro lado, a controlar la homogeneidad de los relatos.

Para lograr credibilidad, aceptabilidad y organización, el ejército cuenta con cuadros profesionales ${ }^{3}$ cuyas producciones tienen la función de seleccionar hechos y personajes, solidificar sentidos y representaciones, olvidar y disimular acontecimientos y períodos para enmarcarlos en los soportes y lenguajes que contribuyan a dar continuidad y coherencia a la narrativa militar. Esta tarea de construcción de 
la memoria institucional exige la utilización de diferentes recursos retóricos, ideológicos y narrativos tales como la reconstrucción política, selección o renegación del pasado, el olvido o disimulo de hechos y sentidos para lidiar con el problema de la justificación que atañe a los procesos históricos que encierran violencia e injusticia.

Pues bien, la memoria institucional del ejército tiene una dinámica que varía en función de las mudanzas de contextos socio-políticos, la aparición de nuevos actores sociales, el surgimiento de relatos y testimonios desconocidos, los cambios en la sensibilidad social, el recambio generacional y las transformaciones en el escenario judicial. De allí que este artículo busca establecer la relación entre cambio y continuidad a partir del análisis de tres momentos en los que la memoria institucional del ejército se cristaliza en documentos y consignas públicas ${ }^{4}$ : la difusión del Documento Final de la Junta Militar sobre la guerra contra la subversión y el terrorismo en 1983, el Mensaje al País del teniente general Martín Balza en 1995 y la consigna de Memoria Completa promovida por el teniente general Ricardo Brinzoni en el año 2000. Asimismo busca dilucidar los siguientes interrogantes: ¿cuáles son los sentidos y verdades que pugnan por ser legitimados? ¿Se afirman continuidades o rupturas respecto de las tradiciones y legados del pasado? ¿Cuáles son los agentes encargados de establecer y difundir la memoria institucional? ¿Con qué actores sociales se enfrenta la memoria del ejército? ¿Cómo influyen los contextos políticos e históricos y los marcos ideológicos en el encuadramiento de la memoria militar?

\section{Negación y triunfalismo}

En el llamado Documento Final de la Junta Militar sobre la guerra contra la subversión y el terrorismo (1983), la última Junta Militar dio a conocer "los resultados y consecuencias de la guerra contra la subversión y el terrorismo". En un mensaje emitido por la cadena nacional de radio y televisión ${ }^{5}$, las Fuerzas Armadas explicaron públicamente las causas de su intervención en la represión y sentaron su posición sobre los desaparecidos. En esta declaración pública, los militares se aferraron a la escena fundante de la dictadura: "la nación en guerra" (Vezzetti, 2002). Es decir, retomaron un punto central de la doctrina que alimentó las representaciones que estallaron en la criminalización del Estado: una guerra por la supervivencia en la cual la defensa de ciertas instituciones y creencias se vuelve la única garantía de "supervivencia de la nación". ${ }^{6}$

Una coyuntura considerada "inédita, excepcional y límite", que ponía bajo amenaza la paz y la integridad de la nación, convertía a las Fuerzas Armadas en el "último recurso para preservar los valores en peligro" frente a las agresiones de un "enemigo moralmente irrecuperable". Este argumento se sostenía además en la creencia inconmovible de que las Fuerzas Armadas eran la última reserva moral de la nación: única institución capaz de "defender el sistema de vida nacional". Además, en el Documento Final, las Fuerzas Armadas explicaron la violencia perpetrada como una respuesta y su intervención como un llamado. Por una parte, la narrativa militar hizo uso del recurso de concebir la propia violencia como una 
respuesta, la única posible en esas circunstancias a la violencia de los otros, a las agresiones de los enemigos de la nación. Y por otra parte, la participación de las Fuerzas Armadas en la represión era presentada como un destino obligado. De este modo, se recreaba una dinámica institucional por la cual las Fuerzas Armadas se vieron obligadas a realizar la tarea para la que estaban moral e históricamente determinadas, aunque siempre en un marco de acción no buscado ni querido por ellas.

Asimismo, con el Documento Final, las Fuerzas Armadas pretendieron resolver dos problemas que se avecinan: la imputación penal y la condena moral. En primer lugar, buscaban rechazar la imputación de responsabilidad criminal por la desaparición de personas ya que ninguna acción individual sería objeto de investigación penal cuando se definía "el accionar de los integrantes de las Fuerzas Armadas en las operaciones relacionadas [como] actos de servicio". ${ }^{7}$ Esto es, como acciones de carácter militar, ejercidas en el contexto de una guerra y "en cumplimiento de un mandato emergente del Gobierno Nacional". ${ }^{8}$ Este argumento movilizaba los mismos valores y creencias que impulsaron la toma del poder y la represión clandestina ya que reproducía una matriz de sentido por la cual la dimensión ética de los actos quedaba subordinada a la lógica de la guerra y sus resultados militares. Tal como se señala en el siguiente párrafo bajo el subtítulo "los principios y los procedimientos":

"Las acciones así desarrolladas fueron la consecuencia de apreciaciones que debieron efectuarse en plena lucha, con la cuota de pasión que el combate y la defensa de la propia vida genera, en un ambiente teñido diariamente de sangre inocente, de destrucción y ante una sociedad en la que el pánico reinaba".

En segundo lugar, las Fuerzas Armadas pretendieron evitar la condena moral de la opinión pública. Con el argumento de la "guerra no-convencional" se buscaba prolongar los efectos perversos de la represión al reintroducir, en el escenario democrático, la condición fundamental del gesto de desaparición: la negación de la realidad represiva. La retórica de la "guerra no-convencional", por una parte, reenviaba la responsabilidad por las acciones de las Fuerzas Armadas a las víctimas de la represión ilegal, y por otra parte, introducía una falsa distinción entre "métodos injustos" y "fines justos" y entre "muertos" y "muertes inocentes".

En el primer caso, se invertía la estructura relacional del mal en la que el daño cometido por uno encuentra su réplica en el dolor padecido por otro (Ricoeur, 1997: 201). Con el objetivo de convertir a las víctimas en responsables de lo que les ha sucedido, y de este modo, diluir la responsabilidad que le cabe al victimario por lo que ha hecho, el daño se explicaba como una contingencia atribuible al desorden de sus vidas. Y así, como señala Veena Das (1995), el discurso militar concluye que el dolor era igual al castigo y que la irresponsabilidad podía ser redimida por el sufrimiento. Así se afirma en el Documento Final: 
"La experiencia vivida permite afirmar que muchas de las desapariciones son una consecuencia de la manera de operar de los terroristas. Ellos cambian sus auténticos nombres y apellidos, se conocen entre sí por los que denominan "nombre de guerra" y disponen de abundante documentación personal fraguada. Las mismas están vinculadas con lo que se denomina como el "pasaje a la clandestinidad"; quienes deciden incorporarse a organizaciones terroristas lo hacen en forma subrepticia, abandonando su medio familiar, laboral y social. Es el caso más típico: los familiares denuncian una desaparición cuya causa no se explican o, conociendo la causa, no la quieren explicar".

En el segundo caso, el Documento Final reproducía un punto central de la Doctrina de la Guerra Contrainsurgente según el cual los movimientos revolucionarios planteaban una guerra generalizada hasta la aniquilación e implementada por un enemigo indefinido que usa "medios injustos". Ejercidos sistemáticamente, pero en la más estricta clandestinidad, el secuestro y la tortura estarían justificados porque eran las armas de combate impuestas por un enemigo definido como terrorista. De este modo, la retórica militar, al referirse a la tortura como un medio para realizar un fin, la naturalizaba y rutinizaba ${ }^{9}$, tal como se afirma en el apartado titulado "los principios y los procedimientos":

"La naturaleza y características propias de esta forma de ataque sorpresivo, sistemático y permanente, obligaron a adoptar procedimientos inéditos en la guerra afrontada; debió imponerse el más estricto secreto sobre la información relacionada con las acciones militares, sus logros, las operaciones en desarrollo y los descubrimientos realizados".

Por último, la distinción entre los "muertos" y las "muertes inocentes" surgía de la propia retórica de la guerra. Al considerar a los desaparecidos como muertos en enfrentamientos, se diluía la acción clandestina y estatal en el terreno de la operación militar. Estos "muertos" se convertían en "muertes inevitables" y, en cierta manera, necesarias, mientras las otras, las "muertes inocentes", se explicaban por la contingencia de una lucha no querida en la que "se pudieron haber cometido errores" y sobre las que únicamente "el juicio histórico podrá determinar con exactitud a quién corresponde la responsabilidad directa". Veamos estas ideas en el propio Documento Final:

"Las Fuerzas Armadas, de seguridad y policiales actuaron en defensa de la comunidad nacional, cuyos derechos esenciales no estaban asegurados, $\mathrm{y}$, a diferencia del accionar subversivo, no utilizaron directamente su poder contra terceros inocentes, aun cuando indirectamente éstos pudieran haber sufrido sus consecuencias". 
"Que en este marco de referencia, no deseado por las Fuerzas Armadas y al que fueron impelidas para defender el sistema de vida nacional, únicamente el juicio histórico podrá determinar con exactitud a quién corresponde la responsabilidad directa de métodos injustos o muertes inocentes".

En suma, las primeras consideraciones públicas de los militares sobre la represión ilegal se caracterizaron por su tono denegatorio y triunfalista. En primer lugar, se negaba el carácter clandestino y sistemático de la desaparición de personas y la existencia misma de los desaparecidos. Y en segundo lugar, se presentaba un discurso eufemista y victorioso sobre lo sucedido bajo la forma de "un mensaje de fe y reconocimiento a la lucha por la libertad, por la justicia y por el derecho a la vida" para quienes "han soportado con estoica conducta las secuelas de una agresión que no provocaron ni merecieron".

Frente a este intento denegatorio del pasado, los organismos de Derechos Humanos y los sobrevivientes de los centros clandestinos de detención acuñaron la noción de Terrorismo de Estado. Con ella, dieron cuenta no sólo del carácter sistemático de la política de aniquilación, sino que también demostraron la utilización en forma clandestina de los órganos de violencia del Estado. En este nuevo escenario, los testimonios de los sobrevivientes fueron progresivamente reconocidos por la sociedad civil como lugar legítimo de la enunciación de la verdad y, de este modo, su discurso se volvió capaz de exigir por los derechos de las víctimas y por la reparación de los daños. Luego de la investigación realizada por la CONADEP y del Juicio a las Juntas, el ethos de los Derechos Humanos se convirtió en la bandera de la transición democrática (Przeworski, 1995: 13) y se consolidó como principio universalista ligado a la Ley y al Estado de Derecho. Y de este modo, con el imperativo de recuerdo permanente que se plasmó con el "Nunca Más" y la autoridad que impuso el "Juicio a las Juntas", se sentaron las bases para un nuevo origen desde el cual rememorar el pasado en Argentina (Landi et al., 1995). Esto significó una ruptura con el discurso que vigente desde la década del 70 entendía la represión como la continuación de una guerra. Tan pronto como perdió valor social este discurso, la retórica militar de las "muertes merecidas" y las "muertes inocentes" se desvaneció, y sólo quedaron víctimas y victimarios. La violencia perpetrada por las Fuerzas Armadas, una vez deslegitimada la narrativa militar, fue percibida socialmente como una desviación de códigos jurídicos, morales y culturales, sobre todo por no entregar los cuerpos y borrar la identidad (Landi y González Bombal, 1995).

En este contexto adverso al relato militar se desencadenó, entre el 15 y el 19 de abril de 1987, "la rebelión de Semana Santa" que recibió el nombre de "Operativo Dignidad" puesto que buscaba devolverle la dignidad a un ejército entregado "a la vindicta pública orquestada por aquellos que en su oportunidad fueron derrotados". Entre los postulados de la rebelión se destacan los siguientes: 
" $1{ }^{\circ}$ - Se consideran extinguidas las esperanzas de que la actual conducción de la Fuerza ponga fin a las injusticias y humillaciones que pesan sobre las Fuerzas Armadas.

$2^{\circ}$ - El feroz e interminable ataque ha generado el grado de indisciplina, desprecio y oprobio en que se encuentran las Fuerzas Armadas. Éste es tal, que su existencia se ve comprometida si sus hombres no levantan la frente y dicen basta.

$3^{\circ}$ - Exigimos la solución política que corresponde a un hecho político como es la guerra contra la subversión..."10

La principal demanda "carapintada" era evitar que fueran "más camaradas detenidos y escarnecidos sólo por haber combatido y triunfado en una guerra justa y necesaria, gracias a la cual el régimen (democrático) tiene cabida". Esta visión triunfalista del pasado se afirmaba en la creencia de que la supervivencia de las instituciones democráticas se debía a que los militares vencieron en "una guerra justa y necesaria contra la subversión". Además de detener el enjuiciamiento de los oficiales del ejército acusados de violaciones a los Derechos Humanos, los rebeldes buscaban el cese de una supuesta "campaña de desprestigio llevada a cabo por los medios de comunicación", el relevamiento de la cúpula del arma y el reconocimiento de la sociedad a la legitimidad de la "lucha contra la subversión".

Las insurrecciones posteriores, "Monte Caseros" en enero de 1988, "Villa Martelli" en noviembre del mismo año y el levantamiento de 1990 -estos dos últimos al mando del coronel Mohamed Alí Seineldín-, se iniciaron como consecuencia de la disconformidad de los sectores "carapintadas" por los castigos y bajas recibidas por las insurrecciones anteriores. Sin embargo, en los tres casos se mantuvo como principal demanda de los rebeldes que el Estado reconociera la legitimidad de la "lucha contra la subversión" (Acuña y Smulovitz, 1995: 67). Desde la perspectiva "carapintada", el hecho de "haber ganado la guerra" constituía razón suficiente para exigir el reconocimiento político del rol desempeñado por el ejército. No obstante, los "vencedores" en el terreno militar se sentían vencidos en el terreno de la memoria. Esta postura triunfalista sobre el pasado represivo no fue una bandera levantada exclusivamente por los rebeldes sino que reflejó los reclamos de amplios sectores leales del ejército, incluso de los mandos superiores. Sobre todo, porque los "vencedores" no podían admitir que sus comandantes estuvieran presos por sentencia de un tribunal civil, por ello consideraban imprescindible la amnistía, tal como lo demuestra el discurso del Día de Ejército del por entonces comandante en jefe, el teniente general José Caridi:

"El ejército convencido de que fue imprescindible librar la guerra contra la subversión, pide que se instrumenten las medidas políticas que hagan posible una definición positiva de sus consecuencias... Esta victoria le ha costado a la Fuerza un alto precio: varios años de lucha contra un enemigo insidioso, artero y cruel, sus méritos y mártires; la agresión e indiferencia de algunos conciudadanos; la 
condena de sus comandantes y, finalmente, el sometimiento a juicio de numerosos camaradas". ${ }^{11}$

Si bien esta primera década de la transición argentina se cerró con los indultos a los ex-comandantes ${ }^{12}$, de todos modos, el ejército y las otras fuerzas se vieron obligados por la sociedad civil a responder por los desaparecidos. No sólo algunos de sus oficiales tuvieron que afrontar los estrados judiciales sino también la institución tuvo que escuchar acusaciones sobre el robo de bebés y reiteradas denuncias sobre la existencia de los lugares de detención en guarniciones militares y sobre la identidad y trayectoria de los oficiales-represores. Los militares percibieron esta coyuntura de acusaciones y reproches como el retorno de la guerra que, en este nuevo contexto, ya no se libraba en el plano militar sino en el plano ideológico. A estas imputaciones, los oficiales respondieron ratificándose como los verdaderos defensores de las instituciones democráticas frente a la amenaza marxista. En efecto, en los primeros años de democracia, el ejército continuó sintiéndose defensor de la nación, habiendo vencido en la guerra de las armas, aunque no lograba la victoria en la "guerra psicológica". En aquellos años, las Fuerzas Armadas se convirtieron en la institución de la Nación más desacreditada.

\section{2. ¿Autocrítica, arrepentimiento, sinceramiento? Continuidades y discontinuidades en la narrativa del ejército}

El 25 de abril de 1995, luego de que el ex-suboficial del ejército Víctor Ibáñez ${ }^{13}$ declarara en la televisión que se arrojaron al mar personas vivas que estuvieron secuestradas en "El Campito" de Campo de Mayo, el comandante en jefe del ejército, el teniente general Martín Balza, pronunció un discurso institucional en el programa televisivo Tiempo Nuevo. ${ }^{14}$ Haciendo uso de todos los recursos que otorga el lenguaje de la pantalla -el primer plano, la mirada a cámara, las pausas y silencios- (Feld, 1998: 61), el pronunciamiento público del teniente general Balza buscaba mejorar la posición y la imagen del ejército en relación con dos frentes: el externo y el interno. Hacia la sociedad civil, dirigió un "mensaje (...) a la comunidad argentina [con quién] busca iniciar un diálogo doloroso sobre el pasado que nunca fue sostenido". El uso de los recursos escénicos de la televisión le dio al discurso un fuerte tono emotivo e intimista acorde al "mínimo de sinceramiento" con el que buscaba mejorar la imagen de descrédito que alcanzaba a los oficiales del ejército y a la institución en su conjunto. Y hacia el interior de la Fuerza, el pronunciamiento intentó principalmente restituir el "pacto de silencio" alterado por las declaraciones de Ibáñez y otros "arrepentidos"15, así como distinguir a la responsabilidad de los ex-comandantes y de los generales de cuerpo del resto de los cuadros.

A diferencia de la narrativa militar que reproducía una posición denegatoria de los hechos, el Mensaje al País ${ }^{16}$ introdujo un cambio en este continuo narrativo procesista. Si bien estas declaraciones no estuvieron exentas de eufemismos tales como "obtención de información por métodos ilegítimos" o "supresión de la vida", admitieron ante las cámaras de televisión la tortura y el 
asesinato cometidos por oficiales del ejército. Así lo expresa el siguiente pasaje del discurso,

\begin{abstract}
"El Ejército, instruido y adiestrado para la guerra clásica, no supo cómo enfrentar desde la ley plena al terrorismo demencial. Este error llevó a privilegiar la individualización del adversario, su ubicación por encima de la dignidad, mediante la obtención, en algunos casos, de esa información por métodos ilegítimos, llegando incluso a la supresión de la vida, confundiendo el camino que lleva a todo fin justo, y que pasa por el empleo de medios justos".
\end{abstract}

En una coyuntura política caracterizada por un fuerte reconocimiento social a la verdad jurídica que estableció el Juicio a las Juntas, el discurso de Balza buscaba obtener credibilidad y aceptabilidad de parte de la opinión pública. Para ello, no sólo tomó distancia del discurso denegatorio de la desaparición de personas y admitió la ilegitimidad de los actos perpetrados, sino que también se alejó de la interpretación castrense que concibe el tema de los Derechos Humanos como una campaña instrumentada por los subversivos derrotados y montada desde los medios de prensa para desacreditar a la institución. Además, para lograr aceptabilidad entre los oficiales y suboficiales del ejército, el discurso de Balza pretendió recortar y focalizar la responsabilidad por la violencia cometida en la conducción del operativo represivo e impugnar el argumento que popularizaron los comandantes de la dictadura de que la tortura y el asesinato fueron excesos cometidos por los subordinados. Así lo afirma en un pasaje de su alocución,

"Algunos, muy pocos, usaron las armas para su provecho personal. Sería sencillo encontrar las causas que explicaron estos y otros errores de conducción, porque siempre el responsable es quien conduce, pero creo con sinceridad que ese momento ha pasado y es la hora de asumir las responsabilidades que correspondan".

Sin embargo, el párrafo que más cautivó a la opinión pública y que llevó a considerar el discurso de Balza como una "autocrítica del ejército por la represión ilegal"17, fue en el que se afirmó:

"Sin eufemismos digo claramente: Delinque quien vulnera la Constitución Nacional. Delinque quien imparte órdenes inmorales. Delinque quien cumple órdenes inmorales. Delinque quien, para cumplir un fin que cree justo, emplea medios injustos, inmorales".

En este párrafo, el teniente general Balza buscó fortalecer la imagen de un ejército que se reconocía subordinado a la Constitución Nacional y a los poderes civiles. Con el acto performativo de acusar de delincuentes a los oficiales que vulneren la Constitución Nacional, el discurso de Balza pretendió romper con el continuo 
narrativo justificador de los golpes de Estado, y de este modo, alejar al ejército del legado del Proceso de Reorganización Nacional, y por lo tanto, separar a los oficiales democráticos de hoy, quienes "aceptan el disenso y respetan la voluntad soberana", de los comandantes golpistas de ayer. Los oficiales del ejército no eran ya presentados como vencedores de una guerra para salvar a la nación y para defender la democracia, sino como oficiales capaces de respetar la Constitución y la ley. Veamos estas afirmaciones en el Mensaje al Pais:

"La comprensión de estos aspectos esenciales hacen a la vida republicana de un Estado y cuando ese Estado peligra, no es el Ejército la única reserva de la Patria, palabras dichas a los oídos militares por muchos, muchas veces (...). Comprender esto, abandonar definitivamente la visión apocalíptica, la soberbia, aceptar el disenso y respetar la voluntad soberana, es el primer paso que estamos transitando desde hace años, para dejar atrás el pasado, para ayudar a construir la Argentina del futuro, una Argentina madurada en el dolor, que pueda llegar algún día al abrazo fraterno".

Con el propósito de mejorar la imagen desacreditada del ejército, el discurso de Balza avanzó en la crítica de la obediencia ciega como práctica común y reiterada entre los oficiales del ejército. Con ello, buscaba difundir la idea de que los oficiales que comandaba eran capaces de distinguir entre una orden que se ajusta a la ley y a la Constitución y una orden que la quebranta, reforzando, de este modo, la imagen de los oficiales del ejército como hombres con discernimiento moral. Asimismo, el Mensaje al País pretendió atenuar la sensación de que todos los oficiales que estuvieron en actividad durante la dictadura eran sospechosos y que las siguientes generaciones también lo eran en la medida en que eran herederas de tradiciones antidemocráticas.

"El que algunos de sus integrantes deshonraran un uniforme que eran indignos de vestir no invalida el desempeño, abnegado y silencioso, de los hombres y las mujeres del Ejército de entonces".

Pero cabe aclarar que la mayoría de los elogios al discurso de Balza se centraron en la frase "el fin no justifica los medios", que fue repetida en los medios de comunicación y retomada por los funcionarios del gobierno. Esta frase mantenía una fuerte filiación con su antónimo "el fin justifica los medios", consagrada por los ideólogos de la "lucha contra la subversión". Tal como sostiene Feld (1998: 61), la frase "el fin no justifica los medios" naturaliza la represión puesto que al considerar a la tortura, el secuestro y el asesinato como medios que persiguen un fin y no como lo aberrante en sí mismo, acaba reproduciendo, en el plano simbólico, el mismo pensamiento instrumental que torna posible el horror. En otras palabras, lejos de impugnarlo, lo justifica. 
Ahora bien, ¿cuáles son las continuidades que el Mensaje al País mantiene con la narrativa hasta ese momento oficial en el ejército? A pesar del "balance positivo" que diferentes sectores hicieron del discurso de Balza, éste mantuvo cierta continuidad narrativa con la retórica de la "lucha contra la subversión". Por una parte, la violencia represiva era concebida como una respuesta a la violencia "iniciada por el terrorismo demencial" que ha hecho "peligrar al Estado y a la vida de la República":

"Nuestro país vivió una década, la del setenta, signada por la violencia, por el mesianismo y por la ideología. Una violencia que se inició en el terrorismo, que no se detuvo siquiera en la democracia que vivimos entre 1973 y 1976, y que desató una represión que hoy estremece".

Por otra parte, la violencia represiva era conceptualizada como una "lucha entre argentinos". De este modo, el Mensaje al País hizo su contribución a los diferentes nombres: "lucha contra la subversión", "guerra sucia", "guerra no convencional", "guerra antirrevolucionaria", "lucha contra el terrorismo", "guerra fraticida", "lucha entre argentinos", con los cuales, según los contextos, la represión ha sido evocada por la memoria militar para distanciarse del concepto de Terrorismo de Estado. Con la noción "lucha entre argentinos" se reproducía una vez más la afirmación generalizada entre las filas del ejército de que la década del 70 estuvo signada por el enfrentamiento entre dos bandos enemigos que sufrieron la violencia y perdieron vidas humanas. En suma, en el discurso de Balza se igualaban "los bandos" y asemejaba la violencia y, por tanto, se equiparaba a los muertos de "unos y otros" para instalar en el escenario de la memoria el reconocimiento para los oficiales muertos por las organizaciones armadas durante la década de 70 como se puede observar en el siguiente párrafo,

"Respeto por todos los muertos, dejar de acompañarlos con los adjetivos que arrastraron, unos y otros, durante tanto tiempo. Todos ellos ya han rendido sus cuentas, allí donde sólo cuenta la verdad".

$\mathrm{Si}$, por un lado, el discurso de Balza buscó, como ya mencionamos, recortar y focalizar la responsabilidad criminal en la conducción del operativo represivo; por otro lado, pretendió disimular la responsabilidad política de la institución con el argumento de la culpa colectiva. En efecto, con la atribución de responsabilidad colectiva intentó diluir la diferencia de naturaleza entre la violencia ejercida por los hombres del ejército y las prácticas y creencias golpistas y antidemocráticas de amplios sectores de la sociedad argentina.

"Siendo justos, miraremos y nos miraremos; siendo justos reconoceremos sus errores y nuestros errores. Siendo justos veremos que del enfrentamiento entre argentinos somos casi todos culpables, por 
acción u omisión, por ausencia o por exceso, por anuencia o por consejo.

... la culpa de fondo está en el inconsciente colectivo de la Nación toda, aunque resulta fácil depositarla entre unos pocos, para liberarnos de ella".

En tal sentido, con la igualación de la violencia perpetrada por los oficiales del ejército con la complicidad de amplios sectores de la sociedad, el discurso de Balza intentó borrar las diferencias morales entre los grados de participación en la empresa criminal, a la vez que tendió a transformar a los diversos grupos sociales en co-responsables. En este sentido es que el concepto de "responsabilidad de los pueblos" vuelve a todos igualmente inmorales y autoritarios. La atribución de responsabilidad colectiva nace, paradójicamente, más de la necesidad de olvido del pasado que de un discernimiento de las culpas y del reconocimiento de la necesidad de reparación. En otras palabras, lejos de introducir el debate sobre la actuación de cada uno de los actores sociales durante los procesos de violencia, el discurso de la culpa colectiva viene a atribuir una complicidad universal: "donde todos son culpables nadie lo es" (Arendt, 1964: 023268). Y con ello, además, se pretendió legitimar la puesta en práctica de amnistías o reconciliaciones que se justifican por fuera del Derecho pero a través de la estructura política del Estado.

"Este paso no tiene más pretensión que iniciar un largo camino, es apenas un aporte menor de una obra que sólo puede ser construida entre todos. Una obra que algún día culmine con la reconciliación entre los argentinos".

Pues bien, a pesar que la admisión pública de las torturas y los asesinatos representó una ruptura con el carácter denegatorio del relato militar sobre la represión ilegal, el jefe del ejército negó la existencia de listas de desaparecidos en la fuerza que comanda. De un modo igualmente contradictorio, el discurso de Balza tomó distancia del golpe de Estado del 24 de marzo de 1976 pero negó el plan sistemático de desaparición de personas (Mazzei: 2004). Al tiempo, retoma un demanda central de la comunidad militar: la reconciliación.

\section{Los "muertos por la subversión": la autovíctimización del ejército}

Con las leyes de Punto Final y Obediencia Debida y el indulto a los ex-comandantes se cimentó en Argentina un pacto de gobernabilidad por el cual los militares obtuvieron impunidad por las violaciones a los Derechos Humanos no sólo a cambio de obedecer a las autoridades democráticas, sino también de dejar de hacer declaraciones o demostraciones públicas reivindicativas de la "lucha contra la subversión". Paradójicamente, las leyes de impunidad funcionaron también como leyes mordaza. Y así en un giro irónico de la historia, durante la década del 90 se podía condenar a los represores por sus declaraciones públicas pero no por los actos atroces que cometieron ${ }^{18}$ (Payne, 2006: 24). Sin embargo, en estos años de 
ausencia de sanción penal se fortaleció en Argentina un ciclo de obstinada guarda de la memoria de los desaparecidos que dificultó el olvido que esas leyes pretendían decretar (Groppo, 2001: 43). Y en este contexto de activación de la memoria de los desaparecidos y de temeroso silencio de los oficiales de las Fuerzas Armadas y de Seguridad surgió y se fortaleció entre las filas castrenses un imperativo de recuerdo y una nueva narrativa sobre el pasado: Memoria Completa.

La consigna Memoria Completa que hizo pública el jefe del ejército teniente general Ricardo Brinzoni el 5 de octubre de 2000, a propósito del $25^{\circ}$ aniversario del copamiento del Regimiento de Infantería de Monte 29 en la Provincia de Formosa por Montoneros, si bien parece una contradicción semántica con el ocultamiento sobre la verdad y destino de los desaparecidos por parte del ejército, muestra que la memoria castrense tiene una dinámica que se construye en función de las interacciones del tiempo presente. Con esta consigna, el ejército busca posicionarse públicamente frente al fortalecimiento de la memoria de los desaparecidos y disputarle a los organismos de Derechos Humanos la verdad sobre el pasado reciente. A pesar de que existen conflictos internos en torno a quién lleva adelante con mayor compromiso y fidelidad la lucha por la Memoria Completa, el imperativo de recordar se vuelve un elemento aglutinante de toda la comunidad militar. Este imperativo, que es vivido como un "deber de memoria" (Nora, 1993), es enarbolado por todos los sectores de la comunidad militar hasta la actualidad: oficiales retirados, oficiales en actividad, conducción del ejército, familiares y amigos de oficiales muertos ${ }^{19} \mathrm{y}$ asociaciones civiles de Memoria Completa. ${ }^{20}$ La memoria deja pues de ser una categoría exclusiva de los organismos de Derechos Humanos para convertirse también en una categoría nativa de los sectores cívico/militares (Jelin, 2002: 17). Tal como lo afirma el teniente general Ricardo Brinzoni:
“...los que somos más viejos tenemos un recuerdo más completo que los jóvenes, yo he dicho que la parcialidad del recuerdo es tan injusta como el olvido". ${ }^{21}$

Ahora bien, ¿qué es lo que se propone completar la memoria de ejército? Desde una lógica binaria que retoma la retórica del enfrentamiento entre argentinos, la Memoria Completa considera que la memoria hegemónica sobre la década del 70 es "parcial, caprichosa y hemipléjica", es decir, que la memoria de los desaparecidos es una "memoria sectaria". De allí que para el ejército recordar implica completar la memoria nacional con una "verdad que ha sido minimizada, silenciada y ocultada" por sucesivos gobiernos democráticos.

La Memoria Completa es pues como una memoria especular y reactiva que construye una versión del pasado reciente tanto más verosímil cuanto más se refleja y se contrapone a la memoria de los desaparecidos y a la lucha de los organismos de Derechos Humanos. La memoria del ejército retoma las consignas que dieron sentido a la lucha de los organismos de Derechos Humanos durante 30 años: "Memoria", "Verdad" y "Justicia" (Jelin, 1995). Si bien el reclamo de Justicia llega mas tardíamente asociado al procesamiento de oficiales luego de 
la derogación de las leyes de Punto Final y de Obediencia Debida ${ }^{22}$, los lemas de "Memoria" y "Verdad" surgen más tempranamente para dar coherencia a la narrativa castrense sobre el pasado reciente.

Con la consiga Memoria Completa se institucionaliza el recuerdo de la "lucha contra la subversión". En otras palabras, el recuerdo vivo del pasado se vuelve política de memoria de la institución castrense. Pero, ¿qué es lo que recuerda el ejército de aquel pasado de violencia? La memoria militar se concentra en el recuerdo de sus propios sufrimientos, ignorando los sufrimientos que la represión ilegal provocó a miles de hombres y mujeres. El libro de tres volúmenes dirigido por el general de división (RE) Ramón Diaz Bessone, In Memorian, que se ocupa de describir las circunstancias en que perdieron la vida los hombres del ejército y sus familiares, marca en este sentido un punto de inflexión. Si bien es una publicación realizada por el Círculo Militar en 1998 y compilada por su presidente y ex-ministro de Planeamiento del régimen militar, y no de un documento con carácter oficial como el Documento Final y el Mensaje al País, se trata de un libro homenaje a los "muertos por la subversión" que sienta las bases para la consigna de Memoria Completa.

En sus páginas, el pasado de violencia y represión resulta re-narrado como una sucesión de martirios que le acaecieron a los oficiales y sus familias. ${ }^{23}$ Con ello busca delegar toda la violencia al "enemigo" para presentar una imagen virtuosa, sacralizada y pasiva de la institución castrense. De allí que la evocación del pasado se enuncia a partir del recuerdo de los "muertos" y, además, la memoria de "muertos por la subversión" se activa, al igual que la memoria de los desaparecidos, como una lucha contra el olvido.

"Pretendemos que no sean olvidados los mártires que verdaderamente sirvieron a nuestra sociedad, al precio de sus vidas y del sufrimiento que aún sobrellevan, como los de nuestros lisiados o de quienes sufrieron pérdidas irreparables"(Díaz Bessone, 1998: 10).

La figura de los "muertos por la subversión" tiene su antecedente en las misas que convocaba la organización política Familiares y Amigos de Muertos por la Subversión (FAMUS) durante los primeros años de democracia. Esta asociación organizaba misas mensuales que contaban con la presencia de oficiales y suboficiales, en retiro y actividad, -muchos de ellos acusados de violaciones a los Derechos Humanos- y de civiles. Estas misas surgieron como una respuesta al inicio de las causas judiciales a ex-represores y al informe sobre la desaparición de personas de la CONADEP, y buscaban reivindicar lo actuado en la "lucha contra la subversión" a partir de la imagen de los oficiales y del ejército como víctimas de la guerrilla.

Con la evocación de los oficiales muertos como mártires de la nación, la memoria del ejército pretende obliterar la represión ilegal y las acciones atroces que cometieron sus hombres para fortalecer una imagen no violenta de la institución como víctima de la agresión terrorista. En tal sentido, para que el ejército se ima- 
gine a sí mismo como una comunidad de víctimas y para que relate la historia reciente como una sucesión de calamidades y sufrimientos, es necesario borrar algunos recuerdos y fundar nuevos (Portelli, 2003). Para inventar esta tradición mnémica, el ejército debe construir una figura ideal del oficial-víctima de la subversión. Esta figura tiene que ser vaciada de ambigüedades políticas y morales y purificada al punto de la inocencia para reemplazar en el panteón de los héroes militares a las figuras inmorales y antidemocráticas de los generales del Proceso de Reorganización Nacional por víctimas inocentes y anónimas. Tal como afirma Díaz Bessone en el prólogo de In Memorian:

"Esta obra tiene por finalidad rendir el homenaje que se merecen quienes han ofrendado sus vidas en defensa de la sociedad argentina en una lucha que culminó durante la aciaga década de los años setenta" (Díaz Bessone, 1998: 9).

Con una fuerte voluntad fundacional, la política de Memoria Completa pretende desterrar de los recuerdos de la institución y de sus prácticas conmemorativas tanto a los hechos como a los oficiales que propiciaron el golpe de Estado del 24 de marzo de 1976. Y de este modo, continuar evocando la "lucha contra la subversión" pero a partir de la figura de los "oficiales caídos en defensa de las instituciones democráticas" antes de 1976. En otras palabras, el ejército busca reemplazar el discurso triunfalista y glorificante del golpe del Estado que llevó a "la victoria en la guerra antisubversiva" por un discurso dramático del sufrimiento y dolor de los oficiales y sus familias que produjo una "guerra fraticida".

La Memoria Completa pretende instaurar pues un conjunto de prácticas evocativas que le permitan al ejército mantener una continuidad narrativa con el pasado y que refuerce, a su vez, su autovaloración como comunidad moral que puede ser transmitida a las nuevas generaciones. No obstante, la memoria de los "muertos por la subversión" sólo es posible por la desmemoria de los hechos de violencia y horror que perpetraron los hombres del ejército. La cristalización de la memoria militar en la figura de las víctimas acaba resaltando ciertos rasgos de los oficiales y silenciando otros, para fortalecer la idea de que los militares no matan para defender a la patria sino que mueren por ella. En otras palabras, ya no se trata de oficiales que combaten contra los enemigos de la nación sino de oficiales que no se rinden en su defensa.

En la nómina de los "muertos por la subversión" confeccionada por Díaz Bessone, una niña de 4 años ocupa el lugar protagónico que siempre había ocupado en la memoria militar el secuestro y asesinato del teniente general Pedro Eugenio Aramburu:

"La primera víctima fatal producida por la acción terrorista de las organizaciones subversivas (...) fue una niña de apenas 4 años, hija de un oficial del Ejército Argentino. En el atentado terrorista perpetrado contra el domicilio del capitán David Rene 
Cabrera, resulta muerta su hijita Guillermina de 4 años y con heridas graves su hijo Jerónimo Luis de 6 años" (Díaz Bessone, 1998: 25).

La figura de Aramburu resulta demasiado contradictoria, fuertemente connotada por las disputas entre peronistas y antiperonistas y muy ligada a la imagen golpista y antidemocrática del ejército para continuar siendo la primera y más destacada víctima de la "guerra revolucionaria". Si bien en los memoriales del ejército se resalta "... la valentía y entereza", "la abismal integridad, divinidad e inteligencia" del alto jefe militar en el momento de su asesinato, su figura resulta problemática para construir una imagen respetable y virtuosa de los oficiales del ejército que "murieron por la patria".

Del mismo modo, las figuras del mayor Argentino del Valle Larrabure y del teniente coronel Jorge Ibarzábal, quienes luego de los ataques a la fábrica militar de Villa María y al regimiento de Azul respectivamente, y tras pasar meses secuestrados, fueran asesinados, se han convertido en los mártires de la "lucha contra subversión". Estos oficiales, que se recuerdan como mártires que "cayeron en defensa de la patria", han reemplazado entre las figuras memorables a los "generales del Proceso" como Videla, Viola, Galtieri o Menéndez, quienes resultan un obstáculo simbólico para la construcción del ejército como víctima de la violencia "terrorista subversiva".

Si bien en la redescripción que el ejército hace de la figura de los oficiales "muertos por la subversión" se destaca su condición de soldados preparados para el combate y para morir con valor; sin embargo, en estas narraciones se remarca particularmente su condición de esposos y de padres de familia, puesto que la feminización que implica la figura de la víctima se contrarresta con la masculinización que identifica al militar valeroso con el padre y esposo, pilar fundamental de la familia.

"Solo 3 misivas le fue permitido hacer llegar a su familia. En ellas trataba de infundir ánimo a su señora e hijos e inclusive les hacía llegar consejos de padre impregnados de una profunda fe católica. Los detalles que llegan a nosotros sobre su martirologio, son los mismos que él escribió en hojas halladas en su celda durante el allanamiento posterior a su muerte y la huida de sus captores" (Díaz Bessone, 1998: 123-24).

La evocación de su paternidad prolonga la línea de la victimización hacia las nuevas generaciones. Para la memoria militar, se trató no solo de oficiales jóvenes sino de padres de 3 o 4 hijos según el caso, lo que "deja muchas otras vidas alcanzadas por la tragedia”. La lógica de la filiación reintroduce la figura de la víctima pasiva y feminizada ahora en los hijos y las esposas. Además, la figura memorable de las víctimas ayuda a que los rangos militares, las armas y las facciones políticas, es decir, las jerarquías y las diferencias entre oficiales se desvanezcan frente al idioma del 
parentesco de la gran familia militar. De esta manera, los oficiales "muertos por la subversión" se convierten en símbolo de la unidad y continuidad del ejército en una coyuntura signada por las tensiones entre carapintadas y carablancas, entre oficiales retirados y oficiales en actividad y entre cuadros medios y generalato.

En el proceso de construcción de la memoria de las "víctimas del terrorismo subversivo", el ejército, por un lado, produce una resignificación de los hechos de violencia del pasado reciente; y por otro lado, se presenta en el escenario de la memoria como portador de "otra verdad" con la que busca disputarle a los organismos de Derechos Humanos el sentido sobre el pasado reciente. Mientras la primera estrategia le exige al ejército concentrarse, como ya dijimos, en la evocación de los propios sufrimientos y en el olvido de los sufrimientos que le causaron a miles de personas, la otra lo obliga a construir narrativamente la "otra verdad olvidada y disimulada". El relato militar se presenta discursivamente como un acto revelador de las verdades ocultas y nunca dichas sobre la violencia terrorista, identificando, de este modo, los hechos de violencia de los que "no sólo el ejército sino toda la sociedad" fue objeto. Se trata de resaltar y destacar, con fuerte tono sensacionalista, los secuestros, ataques a cuarteles y regimientos, asesinatos, juicios populares $\mathrm{y}$ atentados cometidos por las organizaciones armadas durante la primera mitad de la década del 70.

"Las agresiones y distorsiones promovidas, aún en la actualidad, tanto dentro de nuestro territorio como desde el extranjero, nos han movido a revivir en la memoria colectiva de nuestros conciudadanos y hacer conocer a los más jóvenes, las imágenes del horror que a diario suscitaban en nuestro país los procedimientos terroristas subversivos: el asesinato como extorsión ideológica, secuestros y robos millonarios como soporte financiero, las sombras y la clandestinidad como forma operativa. En síntesis, el clásico método del terror para someter a una sociedad" (Díaz Bessone, 1998: 11).

En la escenificación de la "otra verdad", la retórica militar despliega una dimensión narrativa y otra espectacular de la memoria. Esta puesta en escena requiere de lenguajes e imágenes que representen la polarización entre agresores y agredidos, entre víctimas y victimarios que se busca hacer ver y oír. A pesar de que la narrativa castrense se presenta como "exenta de subjetividades para dar cabida un rigor histórico", el lenguaje utilizado en la descripción de los hechos es el de la crónica policial. Los sucesos de violencia, uno por uno, incluyendo asesinatos, secuestros, ataques a cuarteles, atentados, son descriptos de manera sangrienta, detallada, sin mediaciones o pudores. Estas descripciones de fuerte contenido morboso se completan con imágenes fotográficas de los oficiales asesinados, con detalle de sus heridas y golpes. En síntesis, se trata de la versión militar del "show del horror"24, cuyo tono sensacionalista y de denuncia funciona como una vía de escape al sentimiento de frustración por el descrédito y desgaste que recayó sobre el ejército. 
Como ya hemos mencionado, la memoria militar se construyó a sí misma en relación especular con la memoria de los desaparecidos. Por ello, en la disputa con los organismos de Derechos Humanos, la narrativa militar busca también imponer un número que pueda competir con el socialmente consagrado de 30.000 desaparecidos. De allí que es común en las publicaciones encontrar cifras tales como: "21642 acciones subversivas", "5212 atentados con explosivos, 1052 atentados incendiarios, 1311 secuestros de explosivos, 1748 secuestros, 1501 asesinatos, 551 robos de vehículos", etc. De este modo, la retórica militar describe la violencia de las organizaciones armadas con conceptos similares a los utilizados para acusar a los militares.

Asimismo, la victimización del ejército se completa con la demonización de los agresores (Lorenz, 2005: 75). El mecanismo de demonización se arraiga en una concepción que explica el mal por la naturaleza pecadora de la condición humana. De allí que son recurrentes las explicaciones sobre las motivaciones del agresor y las referencias a los motivos maléficos irracionales o insanos como característica natural e innata de los "subversivos". "Por amor al odio", "matar por matar" son algunas de las frases que resumen el carácter demoníaco de los agresores: unos "verdaderos chacales". Este discurso demoníaco produce una naturalización de la violencia que desconoce su dimensión política y social y oculta la relación que mantiene con la sociedad que la produjo.

En el ejército, la narrativa de la víctimización funciona como una estrategia para eludir la proscripción que pesaba sobre el discurso militar -y con ello hacer uso del derecho democrático a la libre expresión-, para posicionarse frente a la memoria de los desaparecidos en Argentina y también para que la memoria militar adquiera visibilidad en la sociedad civil. En efecto, el ejército fue construyendo una estrategia narrativa sobre el pasado que le permite por un lado, salir del silencio y del ámbito cerrado de la memoria corporativa para entrar en el escena pública con un discurso verosímil y disputar los sentidos sobre el pasado que se cristalizaron en los últimos 25 años; y por otro lado, renovar su deteriorada imagen con nuevas justificaciones sobre lo actuado que le permitan apuntar al reconocimiento de la sociedad y del Estado.

\section{Construcción, deconstrucción y reconstrucción de las memorias castrenses}

En los ciclos de construcción, deconstrucción y reconstrucción de la memoria institucional del ejército se observan tanto continuidades como rupturas narrativas. Unas y otras son fruto de las negaciones y confrontaciones que la institución castrense mantiene, para dentro, con el relato hegemónico sobre la "lucha contra la subversión"; para fuera, con el discurso de los organismos de Derechos Humanos y la memoria de los desaparecidos. Estas reconfiguraciones muestran no sólo que el pasado resulta interpretado en el contexto de las interacciones del presente, sino que el ejército está en permanente interrelación con otros actores que exceden lo estrictamente institucional.

A pesar de las modificaciones sobre el sentido del pasado reciente, existe en el ejército una narrativa aglutinante y hegemónica que persevera en los tres mo- 
mentos analizados. Es la que concibe la participación del ejército en actividades represivas como una acción de guerra en la que se defendió a la patria de los enemigos internos que la amenazaban (Vezzetti, 2002; Hershberg y Agüero, 2005). La retórica de la guerra permite, a su vez, enmarcar el pasado reciente en el ideal de las "luchas por la independencia" y de la "historia grande de la patria", remitiendo de este modo, a un momento fundacional, casi mítico, en el que el ejército, la nación y la guerra se funden en la gesta patriótica. La retórica de la guerra da cuenta de un trabajo memorial de ligadura, continuidad y articulación entre el pasado y el presente de una comunidad moral que se sostiene de la repetición de sus tradiciones y rituales, pero no carece de historicidad. De allí que, en los últimos 25 años, adquirió diferentes nombres según los contextos en los que ha sido evocada: "lucha contra la subversión", "guerra sucia", "guerra no-convencional", "guerra antirrevolucionaria", "lucha contra el terrorismo", "guerra fraticida", "lucha entre argentinos" o "lucha interna". Si bien todos buscan distanciarse del concepto de Terrorismo de Estado - con el que se demostró el carácter clandestino y sistemático de la política de desaparición-, sus diferencias no son menores y responden no sólo a los contextos interpretativos y políticos en los que el pasado es evocado, sino también a los interlocutores con los que se disputa sentido y al grupo al que se dirige la memoria.

Otra concepción persistente y de fuerte peso institucional es la que entiende la violencia represiva como una respuesta. Así, el ejército busca definir una oposición binaria que separa a agresores de agredidos. La violencia represiva acaba siendo explicada como una consecuencia no deseada pero inevitable frente a la agresión subversiva. Esta concepción se apoya en una periodización que marca su origen histórico a mediados de la década del 60, momento en el que Argentina es objeto de agresiones del "terrorismo marxista internacional" que "intentaba hacer efectivo un proyecto político destinado a subvertir los valores morales y éticos compartidos por la inmensa mayoría de los argentinos". Esta interpretación de la historia argentina desconoce otros elementos políticos y sociales que contribuyeron al estallido de la violencia, tales como la proscripción del peronismo, la sucesión de gobiernos civiles de escaso apoyo popular, los reiterados golpes de Estado perpetrados por las Fuerzas Armadas, las políticas represivas llevadas a cabo por los gobiernos militares, etc.

Entre las discontinuidades de la memoria institucional del ejército, la admisión pública de torturas y asesinatos, que fueran ordenados por la conducción del ejército y ejecutados por oficiales operativos, representa un elemento nuevo en el continuo narrativo procesista. Al punto que llevó a los investigadores a considerar el discurso de Balza como un primer paso hacia la construcción de una memoria institucional alternativa (Mazzei, 2004: 147). Esto produjo, a su vez, manifiestas resistencias de los oficiales procesistas reunidos en el Foro de Generales Retira$\operatorname{dos}^{25} \mathrm{y}$ en el Círculo Militar ${ }^{26}$, quienes no dudaron en considerar al acto de "rendir cuentas" a la sociedad como una traición (Salvi, 2006). Si bien el Mensaje al País marca una distancia con el discurso denegatorio de la desaparición de personas, se presenta como un "mínimo de sinceramiento" que busca culminar en la "re- 
conciliación entre los argentinos". En un gesto que aleja a la verdad de la justicia, esta admisión funciona como un acto performativo que pretende ofrecer "penas" y "disculpas" por los "errores históricos cometidos" a cambio de la reconciliación, olvido o perdón.

Si bien el reclamo de reconocimiento del Estado y de la sociedad civil es una constante en la memoria castrense tanto en el Documento Final como en la consigna de Memoria Completa, este reclamo se enuncia y justifica desde dos figuras distintas: el hecho de considerarse vencedores en la "guerra contra la subversión" y el discurso de la victimización. En los últimos 25 años, el ejército hizo pública su demanda de reconocimiento a la "lucha contra la subversión", pero, en un primer momento, la legitimidad de este reclamo se apoyó en el hecho de sentirse vencedores en la "guerra antisubversiva", y en un segundo momento, surge de los gestos dramáticos que rodean a la figura de las víctimas de la "lucha contra la subversión". Del mismo modo, frente a las imputaciones de autoritarismo y a las acusaciones de genocidio, la construcción de los oficiales del ejército como patriotas, primero, se erigió en torno a la figura de salvadores de la nación, es decir, como soldados que combatieron a un enemigo que amenaza su integridad. Luego, esta figura, si bien pervive en la memoria colectiva de los oficiales del ejército, se disimula en la imagen de los mártires. Los oficiales se convierten en mártires que perecieron por no rendirse ni claudicar en defensa de las instituciones y valores de la nación.

Por último, la propuesta de reconciliación es una constante en el discurso del ejército que, sin embargo, ha sido enunciada desde el olvido y el imperativo de memoria. En un primer momento, la reconciliación se confunde con la amnistía y se activa a partir de la necesidad de olvido de las "secuelas de una guerra que no fue ni querida ni buscada". El olvido tiene en la narrativa militar una dimensión productiva puesto que el futuro deriva de la prohibición de recordar las desgracias para no dar paso a la justicia que es considerada una herramienta de venganza (Loraux, 1989). En un segundo momento, el discurso de la reconciliación se activa nuevamente pero ya no a partir del recurso del olvido sino de la memoria de los propios sufrimientos. A través de un uso corporativo de los padecimientos, el ejército institucionaliza un discurso de la victimización en el que todos los argentinos resultan hermanados en la evocación de los dolores comunes. Y así, en la memoria militar se asiste a una suerte de pasaje por el cual la regla de "todos" es reemplazada por la regla de "nadie". La máxima de la culpa colectiva que sostiene "donde todos son culpables nadie lo es" es sustituida por otra igualmente exculpatoria que afirma: "donde todos son víctimas nadie es culpable".

\section{Referencias}

1. El término "pasado reciente" refiere al período de creciente conflictividad sociopolítica que va de la primera mitad de la década del 70 hasta los años posteriores al golpe de Estado del 24 de marzo de 1976 que da inicio al terrorismo de Estado.

2. La noción de "escenario de la memoria" remite a la relación entre memoria y representación (Feld, 2001: 103). Lo usamos para referir a un espacio en el que diferentes actores presentan un relato verosímil sobre el pasado, y que, por su diversidad, está atravesado por sentidos y prácticas en disputa, 
tensión, relación y reflejo que responden a las posiciones relativas e intereses diferenciados que éstos mantienen.

3. "Hacer la historia" de la institución, de sus hombres, de sus batallas y de sus muertos es una práctica estimulada y valorada por los oficiales. La institución fomenta y premia la sensibilidad histórica de sus hombres y la Historia, en tanto que ciencia del Estado, es para los oficiales el vehículo privilegiado para promover un pasado memorable. Para lo cual, el ejército cuenta con una Dirección de Asuntos Históricos, que reúne tres dependencias: el Servicio Histórico, el Archivo General y el Museo Histórico. Su tarea es vigilar la transmisión regular y continua del pasado militar en la que participan agentes profesionalizados que realizan actividades periódicas tales como jornadas y coloquios, publicaciones de libros y revistas militares, concursos y premios, actos y homenajes. Además, los cuadros profesionales asesoran sobre la realización de documentos, informes, discursos y proclamas de circulación interna y externa a la fuerza.

4. Si bien existe un reconocimiento diferenciado de los legados del pasado y de sus posteriores reconfiguraciones institucionales entre los diversos actores que componen la comunidad militar, esto es, oficiales en actividad -nuevas y viejas generaciones, oficiales retirados, suboficiales, sectores cívico/militares, familiares y amigos de "muertos por la subversión"-, es necesario también identificar las posiciones relativas y conflictos que se producen en torno a la evocación del pasado reciente (Salvi, 2006). Sin embargo, estas luchas de interpretación no son directamente abordadas en este artículo sino tan solo las continuidades y rupturas -aunque también conflictivas- respecto de los legados del pasado a partir del análisis de tres momentos paradigmáticos en los que la memoria de la institución se hace pública.

5. El Documento Final fue emitido el 28 de abril de 1983 a las 20 hs. Los fragmentos de dicho Documento citados en este artículo fueron extraídos del CD-ROM del libro de J. D'andrea Mohr (1999), Memoria Debida. Buenos Aires, Colihue.

6. En la ideología de la seguridad nacional, la guerra contra-revolucionaria es concebida como una guerra por la supervivencia hasta la destrucción total del enemigo. Esta es su meta final (Comblin, 1977: 35-36).

7. E1 24 de septiembre de 1983, la Junta Militar sanciona la Ley de Pacificación Nacional (Autoamnistía), que fuera derogada el 29 de diciembre del mismo año por el congreso nacional a instancias del poder ejecutivo.

8. El Documento Final se refiere al Decreto $N^{\circ} 261$, del 5 de febrero de 1975 , que ordenaba “... ejecutar las operaciones militares que sean necesarias a efectos de neutralizar y/o aniquilar el accionar de los elementos subversivos que actúan en la provincia de Tucumán", y al Decreto № 2772, del 6 de octubre de 1975, que ordenaba "... ejecutar las operaciones militares y de seguridad que sean necesarias a efectos de aniquilar el accionar de los elementos subversivos en todo el territorio del país".

9. Se trata de un tipo de valoración que disocia medios de fines, así los dispositivos erigidos para provocar sufrimiento y muerte son concebidos como medios para alcanzar un fin.

10. Proclama de la rebelión "carapintada", 17 de abril de 1987. El fragmento fue extraído de H. Verbitsky (1987), Veinte años de proclamas militares, Buenos Aires, Editora/12.

11. Discurso del Día del Ejército, 29 de mayo de 1987. El fragmento fue extraído de J. Greco y G. González (1990), Argentina: el Ejército que tenemos, Buenos Aires, Editorial Sudamericana.

12. El 23 de diciembre de 1990, el presidente Carlos Menem da curso a su anunciada voluntad de indultar a los ex-comandantes, a los generales Camps, Suárez Masson y Richieri, al dirigente montonero Mario Firmenich y a otros civiles, a pesar de que la sociedad civil no respaldaba esta medida.

13. Programa televisivo Hadad \& Longobardi, abril de 1995.

14. El 4 de mayo de 1995 el jefe de la armada, almirante Enrique Molina Pico, hizo público un mensaje en el que admitió los "horrores inaceptables" cometidos por su fuerza durante la represión y asumió que fue un "error histórico" el golpe de Estado del '76. Ver www.nuncamas.org/document/document.htm. El titular de la fuerza aérea, brigadier general Juan Paulik, también admitió los "horrores" cometidos por los oficiales aunque aclaró que fueron "patrimonio de ambas partes".

15. El impulso para producir este documento institucional habría provenido de un grupo de asesores luego de las declaraciones de ex -capitán de corbeta Alfredo Scilingo (Mazzei, 2004: 148). 
16. Ver CD-ROM con base documental del libro de J, D'andrea Mohr, (1999), Memoria Debida, Op. Cit.

17. Titular de Clarín del 26 de abril de 1995.

18. Se trató de las ya mencionadas declaraciones mediáticas del ex-sargento Víctor Ibáñez en abril de 1995, de las apariciones del ex-capitán de corbeta Adolfo Scilingo en el programa de televisión Hora Clave el 9 de marzo de 1995 -así como la edición del libro El vuelo del periodista Horacio Verbitsky-, del ex-policía Julio Simón en Telenoche Investiga en mayo de 1995, del ex-comisario Miguel Etchecolatz en el programa de televisión Hora Clave, del 25 de agosto de 1997 y las afirmaciones del ex-capitán de fragata Alfredo Astiz en enero de 1998 en la revista Tres Puntos y las audiencias públicas de Antonio Pernías y Juan Carlos Rolón en el Senado de la Nación en octubre de 1994.

19. Los familiares y amigos de los oficiales muertos se reúnen en diferentes agrupaciones tales como la Asociación de las Víctimas del Terrorismo en Argentina (ATVA) y Familiares y amigos de víctimas del Terrorismo (FAViTe).

20. Se trata de organizaciones civiles, asociaciones sin fines de lucro y fundaciones como Argentinos por la Memoria Completa, Grupos de Amigos por la Verdad Histórica, Foro por la Verdad Histórica, Jóvenes por la Verdad, Verdad sin Rencor, Argentinos por la Pacificación Nacional (ARPANA) y Asociación Unidad Argentina (AUNAR) que actúan en calidad de portavoces reconocidos o actores oficiosos de los oficiales retirados y de las familias.

21. El Comercial, 5 de octubre de 2000.

22. En octubre de 2007 el fiscal general de Rosario, Claudio Palacín, presentó ante el Juzgado Federal $\mathrm{N}^{\mathrm{o}} 4$ un dictamen que instruía la apertura de la causa por el secuestro y muerte del coronel Argentino del Valle Larraburre cometidos por el ERP pues sostenía que se trataba de un crimen de lesa humanidad.

23. Federico Lorenz (2005) llama a esta memoria subterránea y latente "vulgata procesista", que tiene su soporte estructurante en la actividad propagandista de apoyo al régimen militar entre 1976 y 1979, y que resurge como una memoria unilateral cuando se discuten aspectos del pasado reciente.

24. La crónica televisiva sensacionalista de los primeros meses de la transición democrática, en la que se mostraba en directo la exhumación de cadáveres $\mathrm{NN}$ de las fosas comunes recibió el nombre de "show del horror".

25. Se formó el 4 de diciembre de 1996 como un grupo de presión con alrededor de 200 miembros y con capacidad para influir a las conducciones de la fuerza.

26. El Círculo Militar es un Club que reúne a oficiales retirados y en actividad del ejército y otras fuerzas, y también, a sus familias que hacia 1997 se convirtió en el portavoz de los oficiales procesistas.

\section{Bibliografía}

C. ACUÑA y C. SMULOVITZ (1995), "Militares en la transición argentina: del gobierno a la subordinación institucional", en O. LANDI et al., Juicio, castigos y memorias. Derechos Humanos y Justicia en la politica argentina. Buenos Aires, Ediciones Nueva Visión.

H. ARENDT (1964), Personal Responsibility under Totalitarian Dictatorship, (Versión Larga) Hannah Arendt's Papers, Washington D. C, The Manuscript Division, Library of Congress.

J. COMBLIN (1977), A ideologia da segurança Nacional. O poder militar na América Latina, Rio de Janeiro, Civilização brasileira.

J. D’ANDREA MOHR (1999), CD-ROM Memoria Debida, Buenos Aires, Colihue.

V. DAS (1995), Critical Events. An anthropological perspective on Contemporary India, New Delhi, Oxford University Press.

R. DÍAZ BESSONE (1998), In Memorian, Buenos Aires, Editora del Círculo Militar.

C. FELD (1998), "La instrumentalización del horror en la Argentina", en Artefacto, № 2, Marzo, Buenos Aires.

(2001), "Memoria colectiva y espacio audiovisual: Historia de las imágenes del Juicio a las ex Juntas Militares (1985-1998)", en B. GROPPO y P. FLIER (comp.), La imposibilidad del olvido. Recorridos de la memoria en Argentina, Chile y Uruguay, La Plata, Ediciones al Margen.

J. GRECO y G. GONZÁLEZ (1990), Argentina: el Ejército que tenemos, Buenos Aires, Editorial Sudamericana. 
B. GROPPO (2001), "Traumatismos de la memoria e imposibilidad de olvido en los países del Cono Sur”, en B. GROPPO y P. FLIER (comp.), La imposibilidad del olvido. Recorridos de la memoria en Argentina, Chile y Uruguay, La Plata, Ediciones al Margen.

E. HERSHBERG y F. AGÜERO (Comps.) (2003), Memorias militares sobre la represión del Cono Sur: visiones en disputa en dictadura y democracia, Madrid, Siglo XXI.

E. JELIN (1995), "La política de la memoria: el movimiento de Derechos Humanos y la constitución de la democracia en la Argentina", en O. LANDI et al., Juicio, castigos y memorias. Derechos Humanos y Justicia en la politica argentina, Buenos Aires, Nueva Visión.

- (2002), Los trabajos de la memoria, Madrid y Buenos Aires, Siglo XXI.

O. LANDI e I. GONZÁLEZ BOMBAL (1995), "Los derechos en la política argentina”, en O. LANDI et al., Juicio, castigos y memorias. Derechos Humanos y Justicia en la política argentina, Buenos Aires, Nueva Visión.

N. LORAUX (1989), "De la amnistía y su contrario", en AAVV., Usos del olvido, Buenos Aires, Nueva Visión.

F. LORENZ (2005), “Recuerden, argentinos': por una revisión de la vulgata procesista", en Entrepasados, Año XIV, Número 28, Buenos Aires.

D. MAZZEI (2004), "El general Balza y la construcción de una memoria alternativa del Ejército argentino", en Anuario $N^{\circ} 20$ Historia, Memoria y Pasado reciente, 2003/2004, Escuela de Historia, Universidad Nacional de Rosario, Homo Sapiens Ediciones.

P. NORA (1993), "Entre memoria e historia" prefacio del vol. I, Les Lieux de Memoria, en Projeto Historia, São Paulo, diciembre, 10.

L. PAYNE (2006), “¿Libertad para los enemigos de la libertad?, en Puentes, № 19, diciembre de 2006, Año 6.

A. PRZEWORSKI (1995), "Presentación”, en O. LANDI et al., Juicio, castigos y memorias. Derechos Humanos y Justicia en la política argentina, Buenos Aires, Nueva Visión.

M. POLLAK (2006), Memoria, olvido y silencio. La producción social de identidades frente a situaciones límite, La Plata, Ediciones al Margen.

A. PORTELLI (2003), "Memoria e identidad. Una reflexión acerca de la Italia posfacista”, en E. JELIN y V. LANGLAND (comps.), Monumentos, memoriales y marcas territoriales, Madrid y Buenos Aires, Siglo XXI.

P. RICOEUR (1997), El simbolismo del Mal, Buenos Aires, Ediciones Megápolis.

V. SALVI (2006), "El horizonte memorial de los oficiales del ejército. Entre héroes y traidores", en Revista Puentes, $\mathrm{N}^{\circ}$ 20, Diciembre de 2006. Comisión Provincial por la Memoria, La Plata.

H. VERBITSKY (1987), Veinte años de proclamas militares, Buenos Aires, Editora/12.

H. VEZZETTI (2002), Pasado y presente. Guerra, dictadura y sociedad en la Argentina, Buenos Aires, Siglo XXI.

Recibido: 22/05/08. Aceptado: 11/11/08. 